\title{
Microtubule Disassembling Through Stathmin Bending Bow: A Molecular Dynamic Study
}

\author{
Maliheh Akbar Moulaee ${ }^{1}$, Majid Monajjemi ${ }^{2, *}$ (D), Jamshid Mehrzad ${ }^{1(D)}$, \\ Alireza Motavalizadehkakhky ${ }^{3}$ (D), Mitra Naeimi ${ }^{4}$ (D) \\ 1 Department of Biochemistry, Neyshabur Branch, Islamic Azad University, Neyshabur, Iran \\ 2 Department of Chemical engineering, Central Tehran Branch, Islamic Azad University, Tehran, Iran \\ 3 Department of Chemistry, Neyshabur Branch, Islamic Azad University, Neyshabur, Iran \\ 4 Department of Biomedical Engineering, Central Tehran Branch, Islamic Azad University, Tehran, Iran \\ * Correspondence: maj.monajjemi@iauctb.ac.ir (M.M.);
}

Scopus Author ID 6701810683

Received: 1.05.2021; Revised: 2.06.2021; Accepted: 4.06.2021; Published: 9.06.2021

Abstract: By this work, molecular modeling has been used to interpret the dynamic instabilities of these macromolecules in their structures. By this investigation, multi-dimension structures of microtubules are fixed in both length and width. Via Monte Carlo simulation, the tubulins have been added from the first side of the tubule towards the opposite side by gradually growing a random position. This method is theoretically accomplished via generating a uniform random number between $(0,1)$ based on the Monte Carlo approach. Our calculations have been done by proper dimension around $5 \times 10$ ${ }^{6}$ meters of length that consists of 2000 tubulin dimers. The structure growth rates are based on soluble tubulin dimer concentration. Hereby all results were run between 6-12 times in our modeling of any conditions. There have been recorded value numbers, average length, free tubulin concentration, and the important data of thermodynamic parameters for each simulation.

Keywords: microtubule; stathmine; Taxol; docking simulation; Monte Carlo simulation.

(c) 2021 by the authors. This article is an open-access article distributed under the terms and conditions of the Creative Commons Attribution (CC BY) license (https://creativecommons.org/licenses/by/4.0/).

\section{Introduction}

The stathmin family protein has a major function in regulating microtubules and also causes cytoskeleton remodeling. In addition, the microtubule turnover increased in response to the cell's needs, such as extracellular signals [1-10].

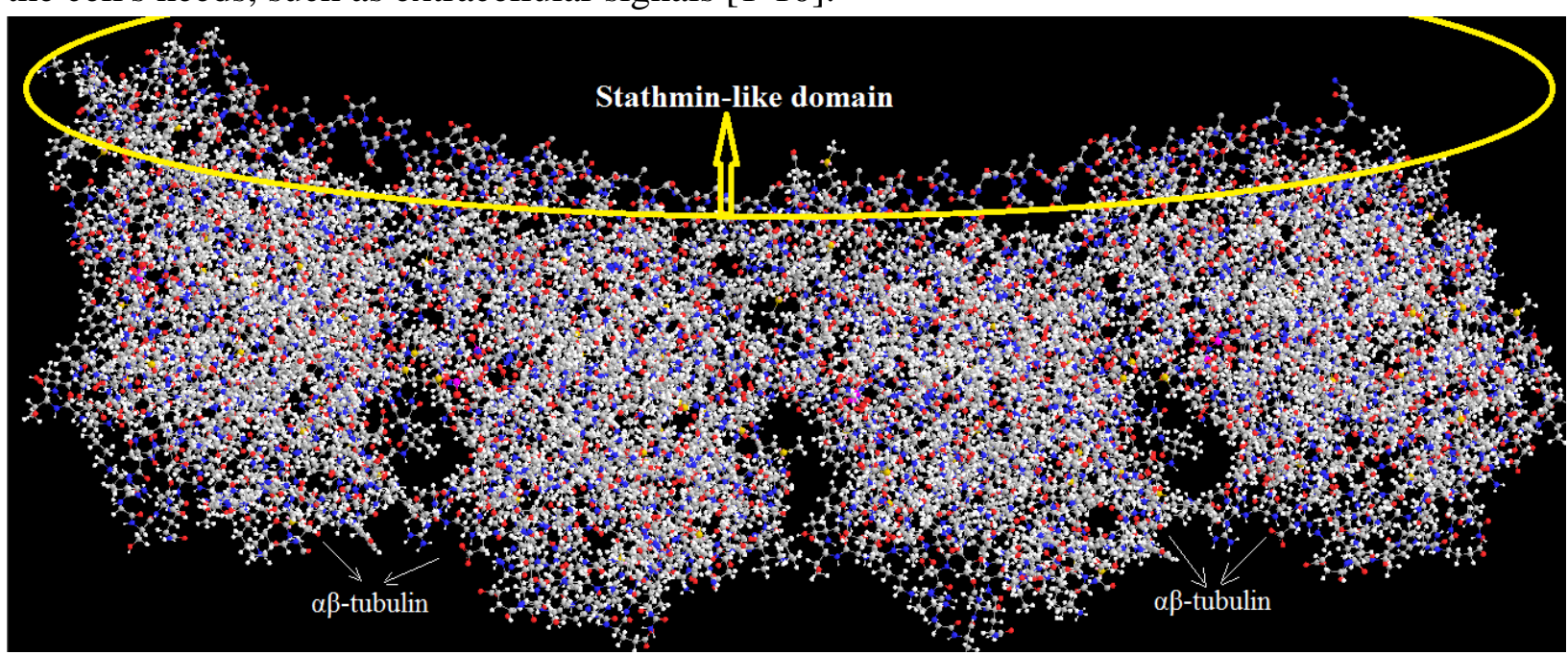

Figure 1. Stathmin-like-domain (SLD) binding to two $\alpha \& \beta$-tubulin.

https://biointerfaceresearch.com/ 
One of the important proteins in microtubules is RB3 in which shares $(88 \%)$ with other members the stathmin-like domain (SLD) (Figure 1) [2, 3]. Since Stathmine families are disordered proteins, and their activities are accomplished via multiple phosphorylation mechanisms, therefore in the T2S complex, tubulin is non-polymerized [4]. However, the stathmin is soluble cytoplasmic macromolecules that regulate rapid microtubule remaking of the cytoskeleton in response to the cell's requirements [5,6].

Recently, special particles have been discovered inside the microtubules, which are not similar to other particles' existence among cell types. Notably, the neuronal cells have the most of these kinds of particles [7-10]. Burton introduces some particles that could be dispensed via lumen quickly through reassembly or disassembly of microtubules [11]. Protein destabilization has been investigated based on stathmin expression in the nervous systems known as SCLIP, SCG10, RB3 (and two of its splice variants RB3' \& RB3") [12-14]. Via EM (electron microscopy), it can be observed that a proto-filament consists of globular 5nm subunits, and it is possible to refined tubulin to assemble with a range of diameters containing between $10-15$ proto-filaments Figure 2.
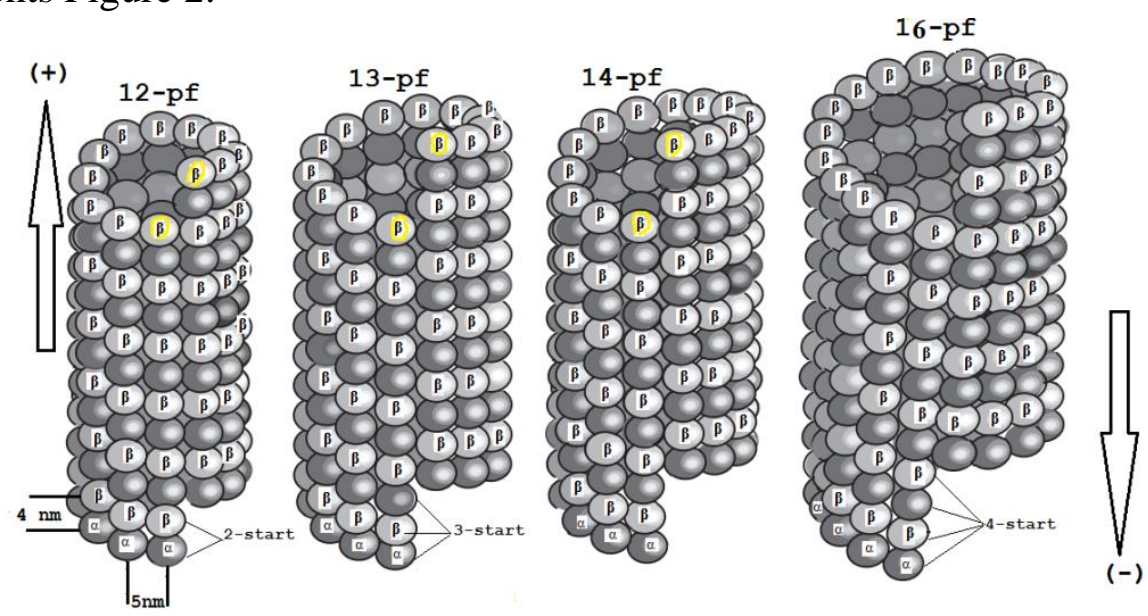

Figure 2. The schematic images of various microtubules, including "12-16" proto-filaments (pf).

Two sub-structures contain $\alpha \& \beta$ tubulins are important in these kinds of assemblies, while the first one is GDP- $\alpha$-tubulin in straight antiparallel proto-filaments stabilized by "Taxol" and the second is the curved structure of two head to tail GDP- $\beta$-tubulin dimers in complex with the stathmin-like domain (RB3-SLD) (Figure 3) [15-18].

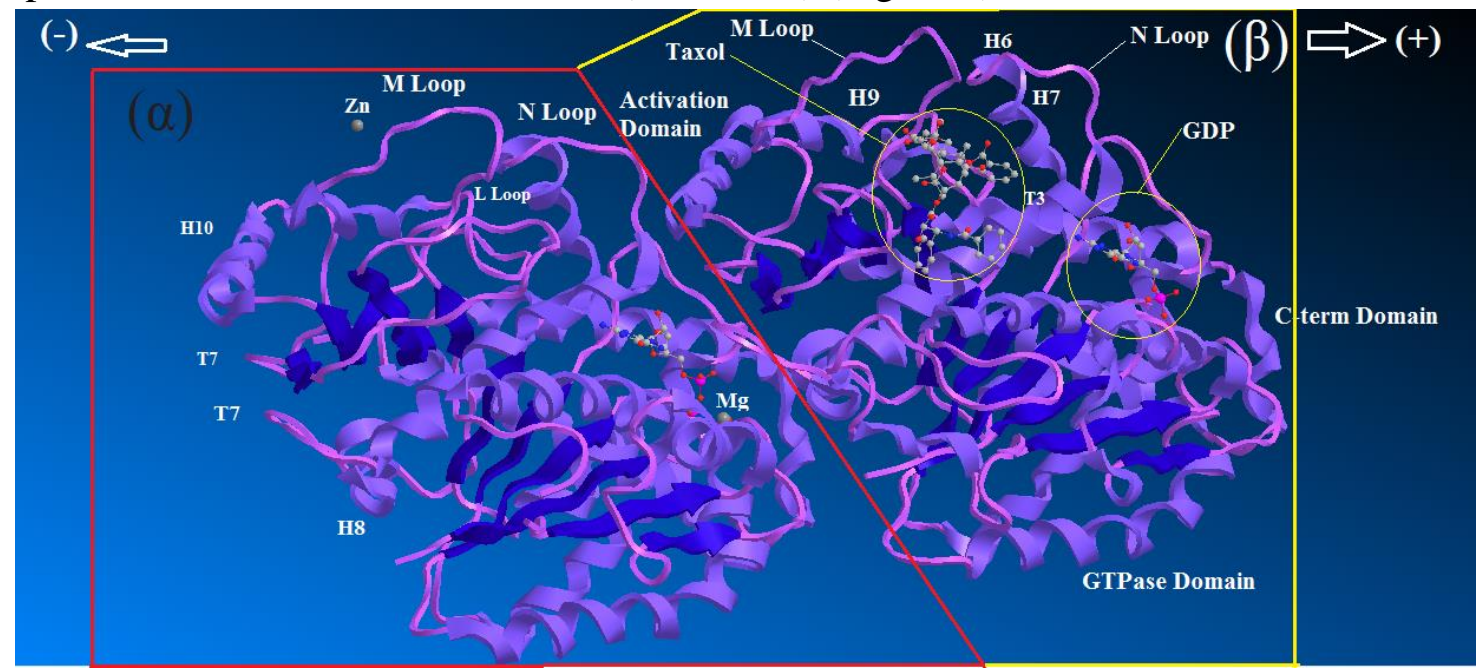

Figure 3. Electron crystallography of two tubulins in complex with Taxol. 
The structures of tubulins in microtubules are related to the straight zinc-sheet structures. Monomers that are near to proto-filaments arrange a collection of shallow helices that, for 13-protofilament microtubules, three shallows run in parallel. This situation causes suitable flexibility in the bonds between adjacent hetero-dimers. Microtubule-associated motor proteins, such as dynein and kinesin, can be run for long distances along a microtubule when there are 14 proto-filaments $[19,20]$. In more or fewer than 14 proto-filaments, the structure might rotate somewhat so that the proto-filaments twisted slowly around the microtubule axis. We simulated our model based on our previous work [21-38].

In recent research, it has been exhibited some important data about the conformational changing of microtubule structures through X-ray crystallography. The C-terminal end of each tubulin polypeptide makes two long helices, and these residues are suitable for isoform recognition through tubulin binding proteins. As it has been shown in Figure 3, the long coil loop is attached in lateral of the proto-filament inside the microtubule. In addition, there is a common agreement that the "M-loop" of one proto-filament makes contact with the GTPase domain. In some locations, the proto-filament makes a ring through bending at all of the interfaces between monomers.

By this study, the kinetic energies, potential energies, and thermodynamic properties of assemblies and dis-assemblies have been done by GTP hydrolysis. This phenomenon confirms that the GTP-tubulins are curved the same as free tubulins and can be moved into the straight conformation through the microtubule. So the $\gamma$-phosphate- GTP has unfavorable Gibbs free energy differences among the curved and straight positions. Consequently, in the allosteric form, "GTP" binding might be induced a straighter conformation pre-combination in water solvent for lateral interactions. Therefore, the lattice form $\alpha \beta$-tubulin adopts a microtubule incompatible, curved conformation independent of the nucleotide state [39-53].

\section{Materials and Methods}

\subsection{Monte Carlo simulation.}

Tubulins-stathmin-like domain complex whit a radius of $25 \mu \mathrm{m}$ and a height of $0.5 \mu \mathrm{m}$ for a volume of around $950 \mu \mathrm{m}^{3}$ has been simulated (Table 1).

Table 1. Common simulation parameters.

\begin{tabular}{l|l|l|l|l|l|l}
$\begin{array}{l}\text { Simulation } \\
\text { temperatures }\end{array}$ & $\begin{array}{l}\text { Random } \\
\text { seeds }\end{array}$ & Run step & Time step & Max delta & $\begin{array}{l}\text { RunTime } \\
\text { ps }\end{array}$ & $\begin{array}{l}\text { Various } \\
\text { Stets }\end{array}$ \\
\hline 300 & 18077 & 100 & 0.05 & 0.05 & 10.0 & $\mathrm{~A}$ \\
\hline 305 & 24000 & 90 & 0.06 & 0.04 & 15.0 & $\mathrm{~B}$ \\
\hline 307 & 22600 & 80 & 0.07 & 0.06 & 12.0 & $\mathrm{C}$ \\
\hline 310 & 20000 & 120 & 0.08 & 0.07 & 14.0 & $\mathrm{D}$ \\
\hline 311 & 25000 & 100 & 0.09 & 0.05 & 9.0 & $\mathrm{E}$ \\
\hline 312 & 30000 & 110 & 0.1 & 0.05 & 11.0 & $\mathrm{~F}$
\end{tabular}

The simple structure was modeled in the basic shape of a generic cell to minimum slip where MTs and Tubulins-stathmin-like domain macromolecule (T-SLD) are dynamically measured. The concentrations of total tubulins were basically set between 30-35 $\mu \mathrm{M}$. T increment the quality of our model, the number of nucleation sites were simulated to 500, which also collected the maximum number of T-SLD. Additional assumptions have been considered as (1)- Tubulins -complete T-SLD de-polymerization immediately opens up that nucleation site for a new nucleation event; (2)- All T-SLD remain associated with their nucleation site 
until they are completely de-polymerize and do not bend during confliction with the cell margin ; (3)- T-SLD destabilization is dependent on free tubulin concentration; (4)- any T-SLD destabilization reaching the cell boundary undergoes a catastrophe. Length decreasing of TSLD can continue to decrease or be based on the liberation phenomenon. Data from this simulation include the number, lengths, and thermodynamic parameters of free tubulins and related mechanisms to their concentration during the simulation. The initial parameters were calculated based on LLCPK1 cells. In addition, end dynamic instability based on Monte Carlo methods is listed in Table 2 (Figure 2).

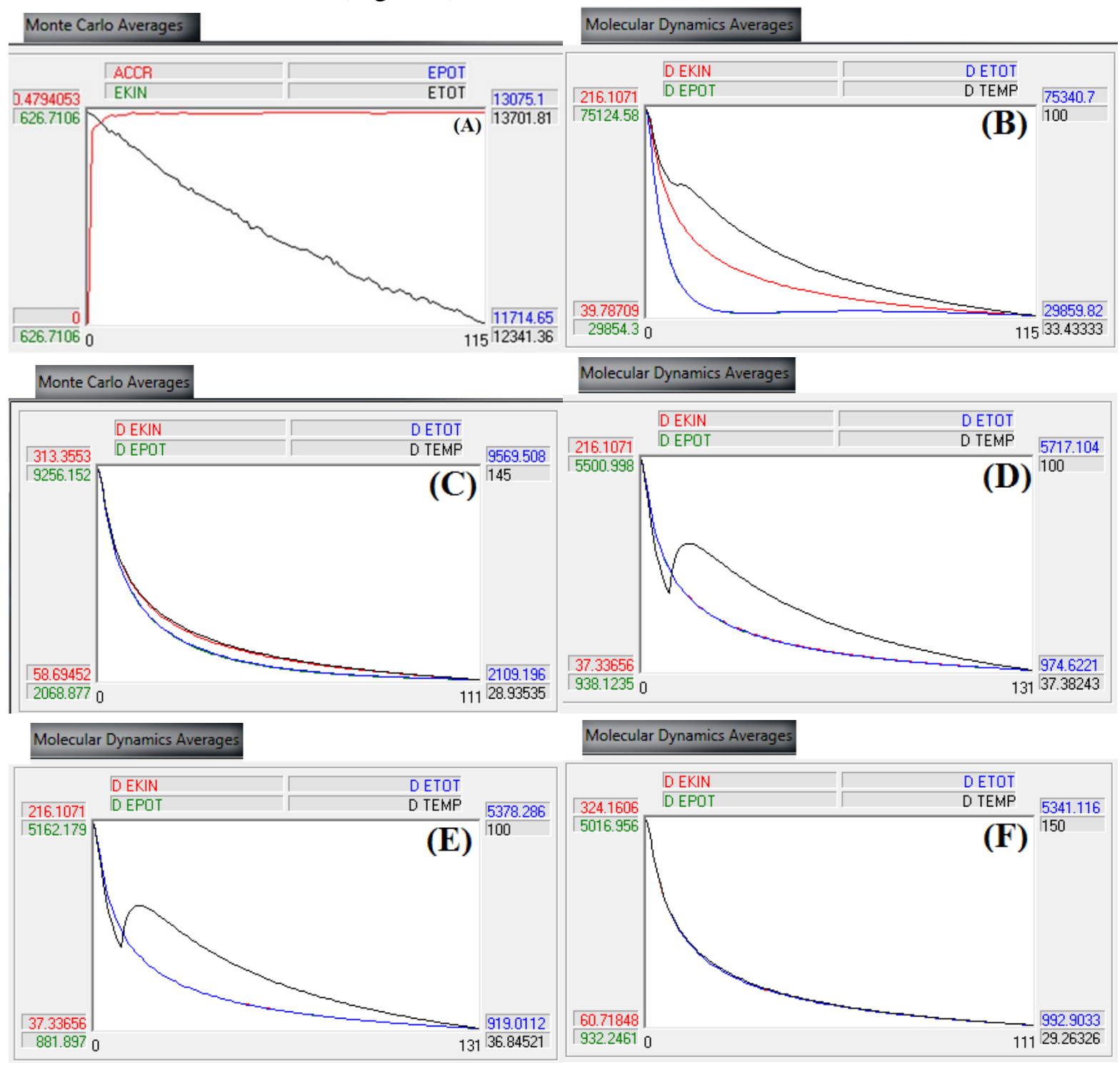

Figure 4. Monte Carlo \& Molecular dynamic simulation of T-SLD in 6 stages.

Table 2. Energies sets for T-SLD end dynamic instability.

\begin{tabular}{l|l|l|l|l}
$\begin{array}{l}\text { Simulation } \\
\text { Temperature }\end{array}$ & $\begin{array}{l}\text { Potential } \\
\text { kcal/mol }\end{array}$ & $\begin{array}{l}\text { Kinetic } \\
\text { kcal/mol }\end{array}$ & $\begin{array}{l}\text { Total } \\
\text { kcal/mol }\end{array}$ & $\begin{array}{l}\text { Various } \\
\text { Stets }\end{array}$ \\
\hline 300 & 13075.1 & 626.7 & 13701.8 & $\mathrm{~A}$ \\
\hline 305 & 75340.7 & 216.1 & 75340.7 & $\mathrm{~B}$ \\
\hline 307 & 9569.5 & 313.3 & 9569.5 & $\mathrm{C}$ \\
\hline 310 & 5717.1 & 216.1 & 5717.1 & $\mathrm{D}$ \\
\hline 311 & 5378.2 & 216.1 & 5378.3 & $\mathrm{E}$ \\
\hline 312 & 5341.1 & 324.1 & 5341.1 & $\mathrm{~F}$
\end{tabular}


As it can be seen in Figure 2a, the releasing of T-SLD length segments is tightly exponential, and T-SLD ends are also limited to a region near the edges. The length of T-SLD can be seen in Figure 2b.

Figure $2 \mathrm{c}$ exhibits a simulation running for several steps to confirm the early steps in T-SLD assembly for a single T-SLD. Medium T-SLD quickly reached about $25 \mu \mathrm{m}$ (Figure $2 \mathrm{~d}$ ). We used the simulations of free tubulin concentration in steady-state amounts through Figure $2 \mathrm{e}$ and the standard deviations of those values also in Figure $2 \mathrm{f}$.

\subsection{Stathmin and microtubule dynamics.}

In intermediate stabilization, MTs are long and until stable due to their slowing dynamic behavior. Belmont [29] explained a model to interpret exerts effects via increasing the amount of these kinds of disasters and, consequently, the microtubule-depolymerized. The mechanism is based on un-polymerized tubulins in ternary stathmin-tubulin complexes (Figure 5). The same group has been extended by showing that the curved complex is capped by the aminoterminal region of the SLD domain. This phenomenon can be blokes the incorporation of the complex into polymerized microtubules. These investigations exhibit that stathmin can potentially attach in both polymerized and un-polymerized tubulins and exclude polymerization towards a stable microtubule.
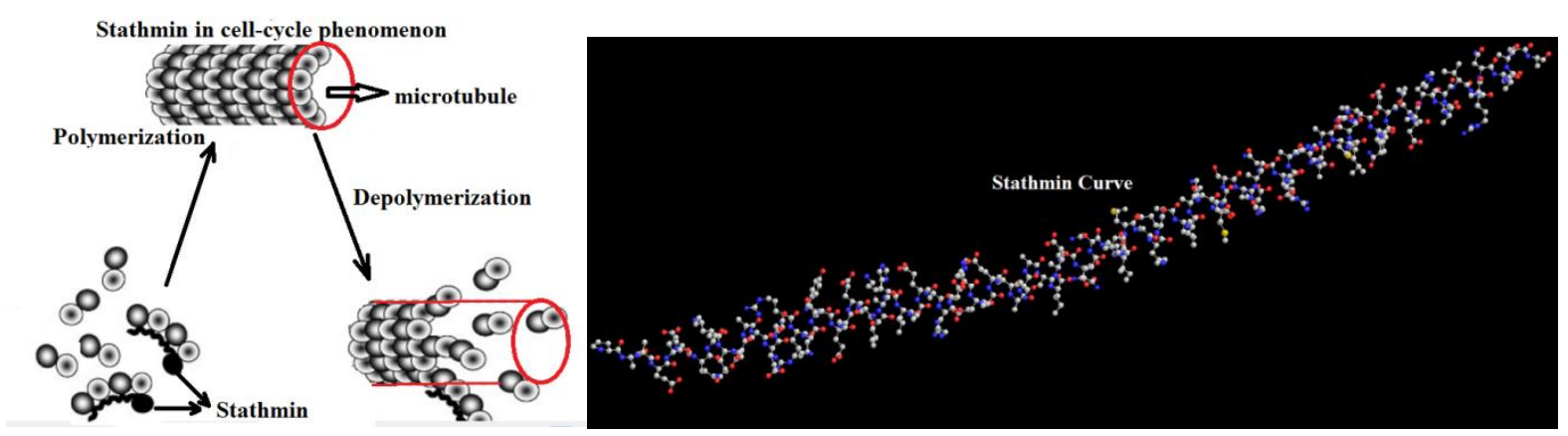

Figure 5. Model for the role of stathmin in the regulation of microtubule dynamics.

\subsection{Estimation of kinetic and free energies.}

The free energy for the association reaction can be calculated via $\Delta \mathrm{G}_{\mathrm{a}}=-\mathrm{RTLnK}$ with the relation of $K=K_{a} / K_{d}$ where, $K_{a}$, is equal for all sites. Therefore a fixed-geometry binding site is applied due to the highest affinity of tubulin-GTP interaction comprising the isolated site. The $\mathrm{K}=\mathrm{K}_{\mathrm{a}} / \mathrm{K}_{\mathrm{d}}$ values can be calculated using estimated free energies values of individual bonds with a definition of association and dissociation sites. The dependences of the two tubulins in a dimer form inside a microtubule structure depend on the number of attached positions and the quality of assembling. The free energies for these binding of Tubulin-GTP at the especial sites can be obtained as the sum of the free energies for individual subunit-subunit interactions among the tubulin monomers. The binding of a molecule of Tubulin-GTP to any typical sites could be normally regarded as involving free energies terms.

\section{Results and Discussion}

In this simulated system, two-dimensional MTs are fixed and modeled for growing tubulins in a random situation on the opposite side. Consequently, at each step, tubulins have been added to the length gradually, one by one, for growing the length. Theoretically, this model can be accomplished via generating a uniform random number between $(0,1)$. 
Comparing the thermodynamic data for dynamical instabilities, including parameter collections, exhibited elongation rates and shortening vary to small degrees. In this study, microtubule formation substitutes among the whole assemblies states and dis-assemblies by random variables of the Monte Carlo approach. $f_{t}$ (A transition frequency) has been defined for a situation of catastrophe and $f_{t^{-1}}$ has been defined from dis-assemblies to assembly. Based on Gibbs energies and some other thermodynamic parameters due to formation and constriction velocities, tubulin concentration has to be described by the simplest stochastic model of field equations to study this matter using Monte Carlo simulation of microtubule length [31]. The accessibility of free $\alpha \beta$-tubulins in the cell pertains to the concentration of the stathmin due to each stathmin binds to two $\alpha \beta$-tubulins towards the ternary structure. However, the system of stathmin is close to the mitotic chromosome due to phosphorylation. Therefore the gradient of stathmin-tubulin interaction moves towards the chromatin, the same as a result reported by Niethmmer experimentally [32]. In this investigation, ordered steps of time can potentially add or subtract one tubulin length for growing microtubules elongation. Therefore the frequencies can be shown as: $f_{\text {catastrophe }}=\frac{f_{t}}{f_{t}+f_{t^{-1}}}$ and $f_{\text {rescue }}=\frac{f_{t^{-1}}}{f_{t}+f_{t^{-1}}}$. The microtubule elongation at a critical time will be in a length situation or simplifying states if the random numbers are less than the normalized transition frequencies for catastrophe, $f_{t}$ or rescue, $f_{t^{-1}}$. Obviously, it must be supposed the transitions to be instantaneous and with a definition of critical length, $L_{\text {critical }}$, $f_{\text {catastrophe }}$ and $f_{\text {rescue }}$ (with an exponential function) are constant. In this position, the velocities of growth are $V_{\text {growth }}$ and for shrinkage $V_{\text {shrinkage }}$ for the microtubules (Table.3).

Table 3. Parameter sets for MT plus end dynamic instability.

\begin{tabular}{l|l|l|l|l|l|l} 
No. & \multicolumn{1}{|c|}{$\begin{array}{c}V_{\text {growth }} \\
\mu m s^{-1}\end{array}$} & $\begin{array}{c}V_{\text {shrinkage }} \\
\mu m s^{-1}\end{array}$ & $\begin{array}{c}K_{a} \\
s^{-1}\end{array}$ & $\begin{array}{c}K_{d} \\
s^{-1}\end{array}$ & $k$ & $\Delta G$ \\
\hline 1 & 0.223 & 0.155 & 0.055 & 0.067 & 0.82 & -494.97 \\
\hline 2 & 0.199 & 0.167 & 0.046 & 0.078 & 0.59 & -1316.1 \\
\hline 3 & 0.213 & 0.188 & 0.064 & 0.081 & 0.79 & -587.94 \\
\hline 4 & 0.191 & 0.149 & 0.057 & 0.066 & 0.86 & -376.18
\end{tabular}

\section{Conclusions}

This work has been simulated and calculated a model dimension around 5×10-6 meter of length consisting of 2000 tubulin dimers. This work shows that the growth index is related to the soluble concentration of tubulin dimers. For all results, it has been confirmed that simulation of any single condition running between 6-12 times is most suitable for any condition. Thermodynamic parameters are most useful for this kind of modeling approach.

\section{Funding}

This research received no external funding.

\section{Acknowledgments}

This research has no acknowledgment.

\section{Conflicts of Interest}

The authors declare no conflict of interest. 


\section{References}

1. Prosser, S.L.; Pelletier, L. Mitotic spindle assembly in animal cells: A fine balancing act. Nat. Rev. Mol.Cell Biol. 2017, 18, 187-201, https://doi.org/10.1038/nrm.2016.162.

2. Chaaban, S.; Brouhard, G.J. A microtubule bestiary: Structural diversity in tubulin polymers. Mol. Biol. Cell 2017, 28, 2924-2931, https://doi.org/10.1091/mbc.e16-05-0271.

3. Janke, C.; Magiera, M.M. The tubulin code and its role in controlling microtubule properties and functions. Nat. Rev. Mol. Cell Biol. 2020, 21, 307-326, https://doi.org/10.1038/s41580-020-0214-3.

4. Akhmanova, A.; Steinmetz, M.O. Microtubule minus-end regulation at a glance. J. Cell Sci. 2019, 132, https://doi.org/10.1242/jcs.227850.

5. Tovey, C.A.; Conduit, P.T. Microtubule nucleation by gamma-tubulin complexes and beyond. Essays Biochem. 2018, 62, 765-780, https://doi.org/10.1042/ebc20180028.

6. Thawani, A.; Kadzik, R.S.; Petry, S. XMAP215 is a microtubule nucleation factor that functions synergistically with the gamma-tubulin ring complex. Nat. Cell Biol. 2018, 20, 575-585, https://doi.org/10.1038/s41556-018-0091-6.

7. Luders, J. XMAP215 joins microtubule nucleation team. Nat. Cell Biol. 2018, 20, 508-510, https://doi.org/10.1038/s41556-018-0100-9.

8. Woodruff, J.B.; Ferreira Gomes, B.; Widlund, P.O.; Mahamid, J.; Honigmann, A.; Hyman, A.A. The Centrosome Is a Selective Condensate that Nucleates Microtubules by Concentrating Tubulin. Cell 2017, 169, 1066-1077.e10, https://doi.org/10.1016/j.cell.2017.05.028.

9. Vemu, A.; Atherton, J.; Spector, J.O.; Moores, C.A.; Roll-Mecak, A. Tubulin isoform composition tunes microtubule dynamics. Mol. Biol. Cell 2017, 28, 3564-3572, https://doi.org/10.1091/mbc.e17-02-0124.

10. Yates, B.; Braschi, B.; Gray, K.A.; Seal, R.L.; Tweedie, S.; Bruford, E.A. Genenames.org: The HGNC and VGNC resources in 2017. Nucleic Acids Res. 2017, 45, D619-D625, https://doi.org/10.1093/nar/gkw1033.

11. Shin, S.C.; Im, S.K.; Jang, E.H.; Jin, K.S.; Hur, E.M.; Kim, E.E. Structural and Molecular Basis for KataninMediated Severing of Glutamylated Microtubules. Cell Rep. 2019, 26, 1357-1367.e5, https://doi.org/10.1016/j.celrep.2019.01.020.

12. Guild, J.; Ginzberg, M.B.; Hueschen, C.L.; Mitchison, T.J.; Dumont, S. Increased lateral microtubule contact at the cell cortex is sufficient to drive mammalian spindle elongation. Mol. Biol. Cell 2017, 28, 1975-1983, https://doi.org/10.1091/mbc.e17-03-0171.

13. Gillard, G.; Roper, K. Control of cell shape during epithelial morphogenesis: Recent advances. Curr. Opin. Genet. Dev. 2020, 63, 1-8, https://doi.org/10.1016/j.gde.2020.01.003.

14. Dogterom, M.; Koenderink, G.H. Actin-microtubule crosstalk in cell biology. Nat. Rev. Mol. Cell Biol. 2019, 20, 38-54, https://doi.org/10.1038/s41580-018-0067-1.

15. Burute, M.; Kapitein, L.C. Cellular Logistics: Unraveling the Interplay Between Microtubule Organization and Intracellular Transport. Annu Rev. Cell Dev. Biol. 2019, 35, 29-54, https://doi.org/10.1146/annurevcellbio-100818-125149.

16. Noordstra, I.; Akhmanova, A. Linking cortical microtubule attachment and exocytosis. F1000Res 2017, 6, https://doi.org/10.12688/f1000research.10729.1.

17. Bernabe-Rubio, M.; Alonso, M.A. Routes and machinery of primary cilium biogenesis. Cell Mol. Life Sci. 2017, 74, 4077-4095, https://doi.org/10.1007/s00018-017-2570-5.

18. Spassky, N.; Meunier, A. The development and functions of multiciliated epithelia. Nat. Rev. Mol. Cell Biol.2017, 18, 423-436, https://doi.org/10.1038/nrm.2017.21.

19. Meiring, J.C.M.; Shneyer, B.I.; Akhmanova, A. Generation and regulation of microtubule network asymmetry to drive cell polarity. Curr. Opin. Cell Biol. 2020, 62, 86-95, https://doi.org/10.1016/j.ceb.2019.10.004.

20. Meaders, J.L.; Burgess, D.R. Microtubule-Based Mechanisms of Pronuclear Positioning. Cells 2020, 9, https://dx.doi.org/10.3390\%2Fcells9020505.

21. Monajjemi, M. Cell membrane causes the lipid bilayers to behave as variable capacitors: A resonance with self-induction of helical proteins. Biophysical Chemistry 2015, 207, 114-127, https://doi.org/10.1016/j.bpc.2015.10.003.

22. Monajjemi, M. Liquid-phase exfoliation (LPE) of graphite towards graphene: An ab initio study. Journal of Molecular Liquids, 2017, 230, 461-472, https://doi.org/10.1016/j.molliq.2017.01.044. 
23. Monajjemi, M.; Naderi, F.; Mollaamin, F.; Khaleghian, M. Drug design outlook by calculation of second virial coefficient as a nano study. Journal of the Mexican Chemical Society 2012, 56, 207-211, https://doi.org/10.29356/jmcs.v56i2.323.

24. Monajjemi, M.; Bagheri, S.; Moosavi, M.S. Symmetry breaking of B2N(-,0,+): An aspect of the electric $\begin{array}{lllll}\text { potential and atomic } & \text { 21636-21657, }\end{array}$ https://doi.org/10.3390/molecules201219769.

25. Monajjemi, M.; Mohammadian, N.T. S-NICS: An aromaticity criterion for nano molecules. Journal of Computational and Theoretical Nanoscience 2015, 12, 4895-4914, https://doi.org/10.1166/jctn.2015.4458.

26. Monajjemi, M.; Ketabi, S.; Hashemian, Z.M.; Amiri, A. Simulation of DNA bases in water: Comparison of the Monte Carlo algorithm with molecular mechanics force fields. Biochemistry (Moscow) 2006, 71, 1-8, https://doi.org/10.1134/s0006297906130013.

27. Monajjemi, M.; Lee, V.S.; Khaleghian, M.; Honarparvar, B.; Mollaamin, F. Theoretical Description of Electromagnetic Nonbonded Interactions of Radical, Cationic, and Anionic NH2BHNBHNH2 Inside of the B18N18 Nanoring. J. Phys. Chem C 2010, 114, 15315-15330, https://doi.org/10.1021/jp104274z.

28. Monajjemi, M.; Boggs, J.E. A New Generation of BnNn Rings as a Supplement to Boron Nitride Tubes and Cages. J. Phys. Chem. A 2013, 117, 1670-1684, http://dx.doi.org/10.1021/jp312073q.

29. Monajjemi, M. Non bonded interaction between BnNn (stator) and BN B (rotor) systems: A quantum rotation in IR region. Chemical Physics 2013, 425, 29-45, https://doi.org/10.1016/j.chemphys.2013.07.014.

30. Monajjemi, M.; Robert, W.J.; Boggs, J.E. NMR contour maps as a new parameter of carboxyl's OH groups in amino acids recognition: A reason of tRNA-amino acid conjugation. Chemical Physics 2014, 433, 1-11, https://doi.org/10.1016/j.chemphys.2014.01.017.

31. Monajjemi, M. Quantum investigation of non-bonded interaction between the B15N15 ring and BH2NBH2 (radical, cation, and anion) systems: a nano molecularmotor. Struct Chem 2012, 23, 551-580, http://dx.doi.org/10.1007/s11224-011-9895-8.

32. Monajjemi, M. Metal-doped graphene layers composed with boron nitride-graphene as an insulator: a nanocapacitor. Journal of Molecular Modeling 2014, 20, 2507, https://doi.org/10.1007/s00894-014-2507-y.

33. Monajjemi, M.; Heshmat, M.; Haeri, H.H.; Kaveh, F. Theoretical study of vitamin properties from combined QM-MM methods: Comparison of chemical shifts and energy. Russian Journal of Physical Chemistry 2006, 80, 1061-1068, https://doi.org/10.1134/S0036024406070119.

34. Monajjemi, M.; Honaparvar, B.; Khalili Hadad, B.; Ilkhani, A.; Mollaamin, F. Thermo-Chemical Investigation and NBO Analysis of Some anxileotic as Nano- Drugs. African journal of pharmacy and pharmacology 2010, 4(8), 521-529. Available online http://www.academicjournals.org/ajpp ISSN 1996-0816 (C)2010 Academic Journals

35. Monajjemi, M., Najafpour, J., Mollaamin, F. (3,3)4 Armchair carbon nanotube in connection with PNP and NPN junctions: Ab Initio and DFT-based studies. Fullerenes Nanotubes and Carbon Nanostructures 2013, 21, 213-232, https://doi.org/10.1080/1536383X.2011.597010.

36. Monajjemi, M., Jafari Azan, M., Mollaamin, F. Density functional theory study on B30N20 nanocage in structural properties and thermochemical outlook Fullerenes Nanotubes and Carbon Nanostructures 2013, 21, 503-515, https://doi.org/10.1080/1536383X.2011.629762.

37. Monajjemi, M.; Ghiasi, R.; Ketabi, S.; Passdar, H.; Mollaamin, F. A Theoretical Study of Metal-Stabilised Rare Tautomers Stability: N4 Metalated Cytosine (M=Be2+, Mg2+, Ca2+, $\mathrm{Sr} 2+$ and $\mathrm{Ba} 2+)$ in Gas Phase and Different Solvents. Journal of Chemical Research 2004, 1, 11-18, https://doi.org/10.3184/030823404323000648.

38. Monajjemi, M., Baheri, H., Mollaamin, F. A percolation model for carbon nanotube-polymer composites using the Mandelbrot-Given curve. Journal of Structural Chemistry 2011, 52, 54-59, https://doi.org/10.1134/S0022476611010070.

39. Kendrick, A.A.; Dickey, A.M.; Redwine, W.B.; Tran, P.T.; Vaites, L.P.; Dzieciatkowska, M.; Harper, J.W.; Reck-Peterson, S.L. Hook3 is a scaffold for the opposite-polarity microtubule-based motors cytoplasmic dynein-1 and KIF1C. J. Cell Biol. 2019, 218, 2982-3001, https://doi.org/10.1083/jcb.201812170.

40. Vuolo, L.; Stevenson, N.L.; Mukhopadhyay, A.G.; Roberts, A.J.; Stephens, D.J. Cytoplasmic dynein-2 at a glance. J. Cell Sci. 2020, 133, https://doi.org/10.1242/jcs.240614.

41. Reck-Peterson, S.L.; Redwine, W.B.; Vale, R.D.; Carter, A.P. The cytoplasmic dynein transport machinery and its many cargoes. Nat. Rev. Mol. Cell Biol. 2018, 19, 382-398, https://doi.org/10.1038/s41580-018-00043. 
42. Sironen, A.; Shoemark, A.; Patel, M.; Loebinger, M.R.; Mitchison, H.M. Sperm Defects in Primary Ciliary Dyskinesia and Related Causes of Male Infertility. Cell. Mol. Life Sci. 2020, 2029-2048, https://doi.org/10.1007/s00018-019-03389-7.

43. Dai, D.; Ichikawa, M.; Peri, K.; Rebinsky, R.; Bui, K.H. Identification and Mapping of Central Pair Proteins by Proteomic Analysis. Biophys. Physicobiology 2020, 17, 71-85, https://doi.org/10.2142/biophysico.BSJ2019048.

44. Okitsu, Y.; Nagano, M.; Yamagata, T.; Ito, C.; Toshimori, K.; Dohra, H.; Fujii, W.; Yogo, K. Dlec1 Is Required for Spermatogenesis and Male Fertility in Mice. Sci. Rep. 2020, 10, 18883, https://doi.org/10.1038/s41598-020-75957-y.

45. Tu, C.; Nie, H.; Meng, L.; Wang, W.; Li, H.; Yuan, S.; Cheng, D.; He, W.; Liu, G.; Du, J.; Gong, F.; Lu, G.; Lin, G.; Zhang, Q.; Tan, Y.-Q. Novel Mutations in SPEF2 Causing Different Defects between Flagella and Cilia Bridge: The Phenotypic Link between MMAF and PCD. Hum. Genet. 2020, 139, 257-271, https://doi.org/10.1007/s00439-020-02110-0.

46. Bustamante-Marin, X.M.; Shapiro, A.; Sears, P.R.; Charng, W.L.; Conrad, D.F.; Leigh, M.W.; Knowles, M.R.; Ostrowski, L.E.; Zariwala, M.A. Identification of Genetic Variants in CFAP221 as a Cause of Primary Ciliary Dyskinesia. J. Hum. Genet. 2020, 65, 175-180.

47. Miyata, H.; Shimada, K.; Morohoshi, A.; Oura, S.; Matsumura, T.; Xu, Z.; Oyama, Y.; Ikawa, M. TestisEnriched Kinesin KIF9 Is Important for Progressive Motility in Mouse Spermatozoa. FASEB J. 2020, 34 , 5389-5400, https://doi.org/10.1096/fj.201902755R.

48. Abdelhamed, Z.; Lukacs, M.; Cindric, S.; Omran, H.; Stottmann, R.W. A Novel Hypomorphic Allele of Spag17 Causes Primary Ciliary Dyskinesia Phenotypes in Mice. DMM Dis. Model. Mech. 2020, 13, 45344, https://doi.org/10.1242/dmm.045344.

49. Cindri'c, S.; Dougherty, G.W.; Olbrich, H.; Hjeij, R.; Loges, N.T.; Amirav, I.; Philipsen, M.C.; Marthin, J.K.; Nielsen, K.G.; Sutharsan, S.; Raidt, J.; Werner, C.; Pennekamp, P.; Dworniczak, B.; Omran, H. SPEF2- And HYDIN-Mutant Cilia Lack the Central Pair-Associated Protein SPEF2, Aiding Primary Ciliary Dyskinesia Diagnostics. Am. J. Respir. Cell Mol. Biol. 2020, 62, 382-396, https://doi.org/10.1165/rcmb.2019-0086OC.

50. Liu, C.; Lv, M.; He, X.; Zhu, Y.; Amiri-Yekta, A.; Li, W.; Wu, H.; Kherraf, Z.E.; Liu, W.; Zhang, J.; Tan, Q.; Tang, S.; Zhu, Y-J.; Zhong, Y.; Li, C.; Tian, S.; Zhang, Z.; Jin, L.; Ray, P.; Zhang, F.; Cao, Y. Homozygous Mutations in SPEF2 Induce Multiple Morphological Abnormalities of the Sperm Flagella and Male Infertility. J. Med. Genet. 2020, 57, 31-37, https://doi.org/10.1136/jmedgenet-2019-106011.

51. Sha, Y.; Wei, X.; Ding, L.; Ji, Z.; Mei, L.; Huang, X.; Su, Z.; Wang, W.; Zhang, X.; Lin, S. Biallelic Mutations of CFAP74 May Cause Human Primary Ciliary Dyskinesia and MMAF Phenotype. J. Hum. Genet. 2020, 65, 961-969, https://doi.org/10.1038/s10038-020-0790-2.

52. Zhao, L.; Hou, Y.; McNeill, N.A.; Witman, G.B. The Unity and Diversity of the Ciliary Central Apparatus. Philos. Trans. R. Soc. B Biol. Sci. 2020, 375, https://doi.org/10.1098/rstb.2019.0164.

53. Legendre, M.; Zaragosi, L.E.; Mitchison, H.M. Motile Cilia and Airway Disease. Semin. Cell Dev. Biol. 2020, 110, 19-33, https://doi.org/10.1016/j.semcdb.2020.11.007. 